Review

\title{
Duodenal Cytochrome b (DCYTB) in Iron Metabolism: An Update on Function and Regulation
}

\author{
Darius J. R. Lane *, Dong-Hun Bae, Angelica M. Merlot, Sumit Sahni and Des R. Richardson * \\ Molecular Pharmacology and Pathology Program, Department of Pathology and Bosch Institute, \\ University of Sydney, Sydney, NSW 2006, Australia; \\ E-Mails: dbae5413@uni.sydney.edu.au (D.-H.B.); angelica.merlot@sydney.edu.au (A.M.M.); \\ sumit.sahni@sydney.edu.au (S.S.)
}

* Authors to whom correspondence should be addressed; E-Mails: darius.lane@sydney.edu.au (D.J.R.L.); d.richardson@sydney.edu.au (D.R.R.); Tel.: +61-2-9351-6144 (D.J.R.L. \& D.R.R.); Fax: +61-2-9351-3429 (D.J.R.L. \& D.R.R.).

Received: 25 October 2014 / Accepted: 5 March 2015 / Published: 31 March 2015

\begin{abstract}
Iron and ascorbate are vital cellular constituents in mammalian systems. The bulk-requirement for iron is during erythropoiesis leading to the generation of hemoglobin-containing erythrocytes. Additionally, both iron and ascorbate are required as co-factors in numerous metabolic reactions. Iron homeostasis is controlled at the level of uptake, rather than excretion. Accumulating evidence strongly suggests that in addition to the known ability of dietary ascorbate to enhance non-heme iron absorption in the gut, ascorbate regulates iron homeostasis. The involvement of ascorbate in dietary iron absorption extends beyond the direct chemical reduction of non-heme iron by dietary ascorbate. Among other activities, intra-enterocyte ascorbate appears to be involved in the provision of electrons to a family of trans-membrane redox enzymes, namely those of the cytochrome $b_{561}$ class. These hemoproteins oxidize a pool of ascorbate on one side of the membrane in order to reduce an electron acceptor (e.g., non-heme iron) on the opposite side of the membrane. One member of this family, duodenal cytochrome $b$ (DCYTB), may play an important role in ascorbate-dependent reduction of non-heme iron in the gut prior to uptake by ferrous-iron transporters. This review discusses the emerging relationship between cellular iron homeostasis, the emergent "IRP1-HIF2 $\alpha$ axis", DCYTB and ascorbate in relation to iron metabolism.
\end{abstract}


Keywords: DCYTB; CYBRD1; vitamin C; cytochrome $b_{561}$; iron homeostasis; anemia; mouse model; HIF2 $\alpha$; IRP1

\section{Introduction}

Iron is critical for cell survival, as demonstrated by cell death following cellular iron-depletion [1,2]. Adult humans contain 3-5 grams of iron, up to $80 \%$ of which is found in erythrocyte hemoglobin, while a further $20 \%$ is stored transiently within macrophages and hepatocytes [3,4]. Cellular iron storage typically occurs within the intracellular iron storage protein, ferritin [5]. The remainder of the iron is present in other heme-containing proteins (e.g., cytochromes), iron-sulfur cluster (ISC)-containing proteins (e.g., succinate dehydrogenase) [6-8] and non-heme/non-ISC iron-containing proteins (e.g., iron- and 2-oxoglutarate-dependent dioxygenases) [9,10]. Approximately $20 \mathrm{mg}$ of iron is required daily for the de novo production of hemoglobin, $90 \%-95 \%$ of which is derived from iron that is recycled from senescent and effete erythrocytes by reticuloendothelial macrophages in the spleen. Approximately $1-2 \mathrm{mg}$ of iron is absorbed in the proximal duodenum to replace iron losses from bleeding, desquamation of epithelial cells, sweating and urinary excretion [4].

Iron in biological systems is typically capable of one-electron redox cycling between its ferric and ferrous forms. While this activity endows iron with much of its biological utility, iron that is not bound in a redox-inert form can catalyze the production of noxious reactive oxygen species (ROS) through Fenton and Haber-Weiss-type reactions [3,11]. As a consequence, iron homeostasis is tightly controlled through regulating its import, storage and cellular efflux [3,12-14].

Ascorbate is a co-factor in numerous metabolic reactions [15]. Humans cannot synthesize ascorbate due to a ubiquitous inactivation of the gene encoding the enzyme, L-gulono- $\gamma$-lactone oxidase (GULO), which is essential for ascorbate synthesis [16]. In addition to ascorbate's capacity to stimulate dietary iron absorption [17], this vitamin also affects iron metabolism by stimulating ferritin synthesis [18] and by inhibiting lysosomal ferritin degradation [19,20] and cellular iron efflux [21]. Further, we have recently shown that the release of ascorbate from ascorbate-replete cells is responsible for ascorbate-stimulated iron uptake from low- $M_{r}$ iron-citrate complexes [15,22,23], which are prominent in plasma of patients with iron-overload disorders [24].

Additionally, ascorbate appears to be involved in the provision of electrons to a family of trans-membrane redox enzymes, namely those of the cytochrome $b_{561}$ class. These hemoproteins oxidize a pool of ascorbate on one side of the membrane in order to reduce an electron acceptor (e.g., non-heme iron) on the opposite side of the membrane. One member of this family, duodenal cytochrome $b_{561}$ (DCYTB/CYBRD1/CYB561A2), may play an important role in ascorbate-dependent reduction of non-heme iron in the gut prior to uptake by ferrous-iron transporters.

The remainder of this review provides an overview of the intestinal absorption of dietary non-heme iron in relation to systemic and cellular iron homeostasis. This discussion will focus on the proposed physiological functions for the intestinal ferrireductase, DCYTB, and the current evidence for a critical role for this reductase in dietary iron absorption. Finally, we examine the emerging iron regulatory 
protein 1 (IRP1)-hypoxia-inducible factor $2 \alpha$ (HIF2 $\alpha$ ) axis and its ability to regulate expression of DCYTB, and other key iron absorption and metabolism proteins.

\subsection{Systemic Iron Homeostasis-An Overview}

Systemic iron homeostasis is largely controlled at the level of iron efflux from three key cell-types into the circulation: (i) dietary iron absorption by duodenal enterocytes (i.e., via reduced iron efflux into the portal circulation); (ii) iron recycling by reticuloendothelial macrophages (i.e., by decreased iron efflux into the plasma following the phagocytic turnover of effete erythrocytes); and (iii) iron release from hepatocytes.

Iron that is released into the circulation by duodenal enterocytes, reticuloendothelial macrophages and hepatocytes is exported by the iron export protein, ferroportin (FPN1) [25]. This iron exporter appears to transport iron in the ferrous form, which helps explain the requirement for ferroxidase activity accompanying iron efflux and iron-loading of transferrin [26]. The amount of FPN1 in major ironreleasing cell-types is modulated in response to iron by multiple mechanisms, including transcriptional and post-transcriptional regulation, and at the level of ligand-induced protein degradation within the autolysosome [27]. The latter is regulated by a key hormone of iron metabolism, hepcidin, which is predominantly produced and secreted by hepatocytes [28]. The binding of hepcidin to FPN1 at the cell surface causes internalization and lysosomal degradation of the hepcidin-FPN1 complex [29]. Interestingly, in the plasma, hepcidin circulates bound specifically to $\alpha_{2}$-macroglobulin and non-specifically to albumin [30]. The binding of relatively small hepcidin peptide to $\alpha 2$-macroglobulin appears to decrease its urinary excretion [31].

The expression of hepcidin is enhanced by iron loading as well as certain inflammatory cytokines, and is suppressed by: iron deficiency and anemia, enhanced erythropoiesis and hypoxia [32]. For recent and comprehensive reviews on the regulation of hepcidin expression and the mechanism of its action, see Ganz and Nemeth [32], and Kautz and Nemeth [33].

\subsection{Dietary Iron Absorption-An Overview}

There is no regulated pathway for iron excretion from the body, and consequently, whole-body iron levels are predominantly controlled at the level of dietary iron absorption from the intestine [34]. Iron absorption occurs mainly in the duodenum (and upper jejunum) and is increased during iron deficiency and decreased during iron repletion and overload [4,35]. At the cellular level, iron is absorbed across the apical membrane of differentiated epithelial cells (enterocytes) of the mid and upper zones of the villus. These cells can absorb dietary iron, which comes in two major forms: non-heme iron, which is mainly found in cereals and vegetables; and heme iron, which is mainly sourced from hemoproteins in meat (for comprehensive reviews of intestinal iron absorption, see Sharp [36] and Gulec et al. [34]). The absorption of heme iron is more efficient than non-heme iron, but the mechanisms remain poorly understood, and will not be reviewed further here.

The uptake of dietary non-heme iron occurs in two phases. In the first phase, iron is taken up across the apical membrane of duodenal enterocytes, which requires that the iron is both soluble and in its reduced form [37]. Dietary non-heme iron, which is typically in the form of low- $M_{\mathrm{r}}$ chelates of ferric iron, is typically liberated as low- $M_{\mathrm{r}}$ iron within the acidic environment of the stomach. The acidic chyme 
is then expelled from the stomach into the duodenum, where the majority of iron absorption is thought to occur. The current and widely-held view is that the reduction of non-heme iron, which is rapidly oxidized into its ferric form in the presence of dissolved oxygen, is mediated by an apical membrane ferrireductase, such as DCYTB [38]: a di-heme transmembrane oxidoreductase that appears to utilize intracellular ascorbate as an electron donor to reduce extracellular ferric iron and other physiological substrates (discussed further below) [15,39,40]. Importantly, there is also evidence that the reduction of non-heme iron in the extracellular environment may involve non-enzymatic ferrireduction driven by endogenous and secreted reductants [37], such as ascorbate [22,23,41] and/or superoxide [42,43]. The contribution of non-enzymatic reduction of duodenal iron by dissolved ascorbate, whether secreted or supplied in the diet, may be of pathophysiological relevance to the mechanism of iron reduction and absorption in mammals (e.g., humans) that are incapable of synthesizing their own ascorbate.

Ferrous iron is then transported across the apical membrane of the enterocyte via a ferrous iron transporter, such as divalent metal transporter 1 (DMT1) [44], and possibly other divalent metal transporters, such as ZIP14 [45]. Iron that reaches the basolateral membrane by poorly understood mechanisms can then be transported into the circulation by FPN1 $[25,46]$. The trans-membrane ferroxidase, hephaestin, colocalizes with FPN1 in the basolateral membrane and, in combination with plasma ceruloplasmin, helps oxidize the exported ferrous iron back to ferric iron $[47,48]$. This iron is then complexed to the major plasma iron transport protein, transferrin (Tf), for transport through the circulation and uptake by distal tissues. Additionally, Tf-bound iron is virtually the sole source of iron for the erythropoietic compartment that is responsible for the daily production of approximately 200 billion erythrocytes [3].

\section{DCYTB and Ascorbate: A Critical Link in Iron Metabolism?}

As recently reviewed [49], in addition to its many roles in cellular physiology, ascorbate is emerging an important modulator of cellular iron metabolism. Indeed, accumulating evidence indicates that, in addition to the known ability of dietary ascorbate to enhance non-heme iron absorption in the gut (see above), ascorbate can actively regulate cellular iron uptake and downstream cellular iron metabolism. In fact, ascorbate is known to regulate iron metabolism by: (i) increasing Tf-dependent iron uptake, possibly via an endosomal reductive mechanism [50], and increasing non-Tf-bound iron uptake, the latter of which occurs by a trans-plasma membrane ascorbate/DHA cycle [22,23,41,50]; (ii) increasing and/or maintaining the levels of IRP1 in its non-iron responsive element (IRE)-binding cytosolic aconitase form, which leads to an increase in ferritin synthesis [18,51]; and (iii) inhibiting lysosomal ferritin degradation via autophagy [19].

Additionally, ascorbate is capable of modulating FPN1 [52] and/or cellular iron efflux activity [21,52]. Indeed, we have shown that ascorbate can decrease iron efflux from various cell-types [21,50], although, whether this iron-efflux is FPN1-dependent is unclear. Considering this, it is notable that near-physiological extracellular ascorbate levels $(100 \mu \mathrm{M})$ caused an increase in FPN1 expression in intestinal epithelial-like human Caco-2 cells, which was associated with an increase in IRP2 and HIF2 $\alpha$ [52]. Whether the increase in FPN1 was due to an ascorbate-dependent increase in ISC formation/retention within IRP1 [51], which could explain the increase in HIF2 $\alpha$ and subsequent increase in FPN1 (see below), is unclear. 
As mentioned above, the other major role of ascorbate in iron metabolism appears to be through its activity in supplying reducing equivalents to DCYTB, a cellular ferrireductase, and perhaps other members of the cytochrome $b_{561}$ family. The potential physiological functions of DCYTB are reviewed below.

\subsection{The Cytochrome b561 Family and DCYTB}

The cytochrome $b_{561}$ family exists in all eukaryotic kingdoms [53]. For an excellent recent review, see Asard et al. [39]. Cytochrome $b_{561}$ (also known as chromaffin granule cytochrome $b_{561}$; CYB561/CYB561A1) catalyzes trans-membranous electron transfer from cytosolic ascorbate to intra-vesicular ascorbyl radicals in neuroendocrine secretory granules [54].

CYB561 was initially recognized as a redox-active component of catecholamine storage granules in the early 1960s [55]. This activity was originally demonstrated to be the result of a unique heme-containing cytochrome located in the membranes of these vesicles [56-58]. In the 1980s, spectroscopic and EPR studies demonstrated that this cytochrome was responsible for equilibrating the ascorbate-ascorbyl radical pair inside the granule lumen with this redox pair in the cytosol [59-61]. Indeed, CYB561 is canonically involved in trans-membranous electron transfer from cytosolic ascorbate to the intravesicular ascorbyl radical in neuroendocrine secretory granules [54,62,63]. The ascorbate that results from this redox reaction can then be oxidized by copper-containing dopamine $\beta$-hydroxylase and peptidyl glycine $\alpha$-amidating monooxygenase [64]. The CYB561-catalyzed reaction involves a histidine cycling mechanism of coupled proton/electron transfer between ascorbate and the ascorbyl radical [65]. A recent atomic level crystal structure of Arabidopsis thaliana cytochrome $b_{561}$ indicates this protein may function as a dimer [66]. Moreover, two highly conserved amino acids, Lys-81 and His-106, play vital roles in substrate recognition and catalysis [66]. Indeed, the structural and biochemical analyses presented in this study probably provide for a more general electron transfer mechanism that is applicable to other cytochromes $b_{561}$ [66].

In addition to DCYTB, additional members of cytochrome $b_{561}$ family of enzymes in mammals include lysosomal cytochrome $b_{561}$ (CYB561A3) [53,67], stromal cell-derived receptor 2 (SDR2/FRRS1) [68,69] and the putative tumor suppressor, 101F6 (CYB561D2/TSP10) [70,71]. Intriguingly, all proteins have been shown capable of stimulating cellular ferrireduction, and are expressed at the plasma membrane, as well as at intracellular sites [38,53,68,72,73]. As with CYB561, these proteins may also be involved in the trans-membrane reduction of the ascorbyl radical with cytosolic ascorbate as the electron donor [39] (Figure 1).

\subsection{What Is the Identity of the Electron Donor for DCYTB?}

While the bulk of evidence suggests that ascorbate is the major electron donor for many of the cytochromes $b_{561}$ [39], a recent report suggests that dihydrolipoic acid can donate electrons to some cytochromes $b_{561}$ under certain conditions [74]. However, there is no direct evidence that dihydrolipoic acid can donate electrons to DCYTB. Although the cellular levels of dihydrolipoic acid are relatively low compared to ascorbate, this activity may be partially responsible for an apparent ascorbate-independent ferrireductase activity of DCYTB [73]. Dihydrolipoic acid may also be involved in intracellular ascorbate recycling [75,76], so the contribution of this molecule to the activity of DCYTB, and other cytochromes $b_{561}$, could potentially occur at multiple levels. 


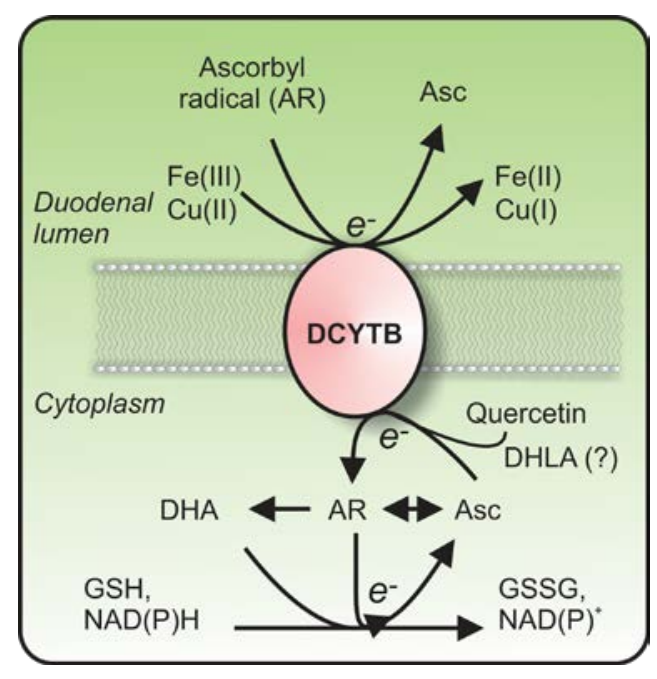

Figure 1. The role of duodenal cytochrome $b_{561}$ (DCYTB) as a transplasma membrane oxidoreductase. DCYTB is transplasma membrane oxidoreductase that reduces either extracellular ferric iron, (Fe(III)), cupric copper (Cu(II)), or the ascorbyl radical (AR), at the expense of intracellular reducing equivalents derived proximally from intracellular ascorbate and/or quercetin, or possibly dihydrolipoic acid (DHLA). The source of reducing equivalents for the recycling of intracellular ascorbate from dehydroascorbate (DHA) or AR includes reduced glutathione (GSH), which becomes oxidized to GSSG, and/or NAD(P)H, which becomes oxidized to $\mathrm{NAD}(\mathrm{P})^{+}$, but also the mitochondrial respiratory chain (not shown). For a review on intracellular ascorbate recycling, see Linster [16] and Lane and Lawen [15].

As DCYTB demonstrates partial conservation of the canonical ascorbate-binding motif originally identified in CYB561 [39,53,64], ascorbate is a likely proximal electron donor for DCYTB-dependent oxidoreduction. Accordingly, several studies in which DCYTB-expressing cells have been supplemented with ascorbate or DHA provide support for this conclusion [53,72,77-79]. However, one study has suggested that ascorbate is not essential, at least in airway epithelial cells [73].

The polyphenolic flavonoid, quercetin, has also been described to function as an electron donor for DCYTB [80]. This finding is significant given that quercetin is considered to be the most prevalent flavonoid in the Western diet [81]. This suggests that quercetin could be a quantitatively significant enterocytic reductant involved in the supply of electrons for DCYTB-dependent ferrireduction in the duodenum. Moreover, quercetin can be imported by facilitative glucose transporter (GLUT) 1 and 4 [82], and reversibly inhibits both glucose and DHA uptake by GLUTs 1-4 [83,84]. An additional consideration here is that quercetin-iron chelates appear to be able to shuttle iron in either direction across the plasma membrane via GLUT1 [85]. This suggests that quercetin is an important dietary factor that may be able to modulate dietary iron absorption by both DCYTB-dependent and -independent mechanisms. An interesting further possibility, which remains to be assessed, is that DCYTB reduces at least some iron in the form of quercetin-iron chelates in the duodenum. 


\subsection{DCYTB: Clarifying Its Role in Iron Metabolism}

DCYTB is an iron-regulated ferrireductase that is highly expressed in the apical membrane of duodenal enterocytes $[38,40]$. This di-heme-protein $[78,86]$ was originally suggested to be responsible for non-heme iron reduction during dietary iron absorption [38,77]. Indeed, it is highly expressed in the brush border membrane of the duodenal microvilli, where it appears to be regulated by iron, hypoxia, erythroid activity and by increased systemic iron requirements [38,40]. Emerging evidence also suggests that a promoter single nucleotide polymorphism in the DCYTB gene is a genetic modifier for the iron overload disorder, HFE hereditary hemochromatosis, possibly leading to a $30 \%$ decrease in promoter activity [87].

Importantly, DCYTB was identified by a subtractive cloning strategy, similar to that used to identify DMT1 [44] and FPN1 [46]. A duodenal ferrireductase had long been suspected to be required for dietary non-heme iron absorption. This notion was subsequently challenged by Gunshin and colleagues with the observation that Cybrd1 ${ }^{-/-}$(i.e., DCYTB-knockout) mice did not develop iron deficiency on a standard lab diet, or develop greater iron-deficiency on an iron-deficient diet, compared to wild-type mice [88]. The results of the Gunshin et al. [88] study are intriguing and are consistent with the likelihood that the activity of DCYTB may be supplemented by the action of other ferrireductases or ferrireductants. Indeed, a likely contributing factor to the apparent lack of phenotype in DCYTB-knockout is the presence of secreted ascorbate in gastric juice [40,89]. Indeed, ascorbate is a normal constituent of such secretions, even in ascorbate auxotrophs, such as humans [90]. As previously suggested, the levels of ascorbate secreted into the gut lumen may be markedly higher in mice and other species capable of synthesizing their own ascorbate [72,89]. Intriguingly, luminal ascorbate levels in the duodenum and duodenal mucosa have been shown to be regulated by iron, as they are increased in iron deficient and hypotransferrinaemic mice as well as by iron deficiency in humans [89,91].

An important caveat to study of Gunshin et al. [88] is that the results obtained do not directly pertain to the role of DCYTB in dietary iron absorption [92]. That is, although the inactivation of DCYTB does not alter hepatic iron levels of mice fed on a standard diet over the time-course examined, the standard chow employed contains high amounts of ferrous iron [92]. If DCYTB acts as a ferrireductase in the duodenum that is required to reduce ferric to ferrous iron prior to uptake by DMT1, the requirement for the activity of this protein under such conditions may be minimized. As previously suggested [92], additional important information would be obtained by examining the effect on hepatic iron stores of a diet containing exclusively ferric iron. Moreover, the role of DCYTB in iron absorption should be directly assessed through radioactive tracer studies in which normal or iron-deficient chow is supplemented with radioactive ferric iron [92].

As discussed further below (Section 3.3), DCYTB is strongly upregulated by hypoxia in a HIF2 $\alpha$-dependent manner. This suggests that the physiological significance of DCYTB in dietary iron absorption may be more apparent under conditions of hypoxia compared to normoxia. Indeed, a recent study from McKie's group assessed the contribution of murine DCYTB to total duodenal ferric reductase activity, as well as to whole-animal iron metabolism, in the context of hypoxia [93]. They found that DCYTB was likely to be the only hypoxia-inducible ferrireductase in the duodenum, as there was no evidence of hypoxia-inducible ferrireductase activity in $\mathrm{Cybrd1}^{-/-}$mice. Interestingly, while hematological indices and liver non-heme iron levels were unaffected in wildtype compared to Cybrd1 $1^{-/}$ 
mice under conditions of hypoxia, spleen non-heme iron levels in the Cybrd1 $1^{-/}$animals were almost half that of the wildtype animals [93]. Additionally, under conditions of normoxia, Cybrd1 $1^{-/-}$mice exhibited evidence of impaired reticulocyte hemoglobinization [93]. These findings strongly suggest that DCYTB is the primary iron- and hypoxia-regulated duodenal ferrireductase, and that this protein is required for optimal iron absorption and systemic iron metabolism.

\subsection{Does DCYTB Play a Role in the Reduction of Copper and Ascorbyl Radicals?}

DCYTB has also been suggested to function as an oxidoreductase in a variety of tissue and cell-types [38,72,77,78]. These include human erythrocytes [94], airway epithelial cells [73], K562 cells [95-97], Hep-G2 cells [96], Caco-2 cells [79,96], and astrocytes [98,99]. This suggests a more general function for DCYTB than one of just enhancing dietary non-heme iron absorption. Several important studies have implicated DCYTB as a more general oxidoreductase, potentially involved in the cellular reduction of not only non-transferrin-bound iron and non-heme iron, but also copper and ascorbyl radicals. These studies are briefly reviewed below.

A role for an apparent DCYTB homologue in rabbit duodenal enterocytes [100] as a cell-surface cupric reductase has been proposed [72]. Indeed, MDCK cells heterologously and inducibly expressing DCYTB-EGFP at the plasma membrane demonstrated an enhanced ability to reduce both ferric and cupric ions [72]. These cells also endogenously express DMT1 and demonstrated an increased rate of ${ }^{59} \mathrm{Fe}$ uptake from low- $\mathrm{Mr}_{\mathrm{r}}{ }^{59} \mathrm{Fe}-\mathrm{NTA}$ or ${ }^{59} \mathrm{Fe}$-citrate [72], the latter of which is a physiological low- $M_{\mathrm{r}}$ iron chelate [3]. As dietary copper must also be in the reduced form to be absorbed [101], these findings suggest that DCYTB may also act as an intestinal copper reductase that helps to augment dietary copper absorption by supplying cuprous ions for uptake by either copper transporter 1 [102] or DMT1 [103,104].

Copper and iron metabolism are intimately connected [101,105], particularly via the two multicopper ferroxidases, hephaestin and ceruloplasmin. Indeed, a recent study has demonstrated that copper deficiency leads to anemia, duodenal hypoxia, and the up-regulation of HIF2 $\alpha$ and HIF2 $\alpha$-regulated iron absorption genes in mice (e.g., Cybrd1, Dmt1 and Fpn1) [105]. Moreover, iron deficiency in mice leads to up-regulation of copper absorption genes (Atp7a and Mt1) [106]. Indeed, the enterocyte ATP-dependent copper exporter, Atp7a, is upregulated at the transcriptional level by HIF $2 \alpha$ in intestinal epithelial cells [107]. A more recent study suggests that HIF2 $\alpha$-dependent upregulation of Atp7a during iron deficiency/hypoxia also requires the transcription factor, Sp1 [106]. Thus, the putative activity of DCYTB as a cupric reductase suggests a further connection between iron and copper metabolism, as well as a connection between ascorbate and copper metabolism. The role of HIF $2 \alpha$ in regulating intestinal iron absorption will be discussed in more depth in Section 3.3.

Another important physiological electron acceptor for DCYTB appears to be the ascorbyl radical [94], which is the one-electron oxidized form of ascorbate. DCYTB also shows conservation of the predicted ascorbyl radical binding site, suggesting that it may be an additional native electron acceptor. Indeed, in similarity to CYB561, the putative DCYTB ascorbate-binding site maps to the cytosolic side of the membrane, while that of the ascorbyl radical binding site maps to the extracellular face [53,64]. This at least indicates that DCYTB-dependent catalysis of ascorbate:ascorbyl radical reduction is topologically plausible. Indirect experimental support for DCYTB-dependent ascorbyl radical reduction comes from an important study that identified DCYTB in human erythrocyte membranes [94]. Indeed, Su et al. [94] 
also determined that DCYTB occurs in erythrocyte membranes from guinea pigs, which, like humans, cannot produce their own ascorbate, but not erythrocyte membranes of rats and mice. Critically, both rats and mice are able to produce their own ascorbate, suggesting that the existence of DCYTB in the erythrocyte membrane is determined by the lack of ascorbate biosynthetic ability of that animal, and potentially, circulating ascorbate levels. Importantly, DCYTB-containing human erythrocytes were much more effective at preserving extracellular ascorbate than mouse erythrocytes. These findings suggest that the presence of DCYTB in erythrocytes from ascorbate auxotrophs (e.g., humans and guinea pigs) is an important adaptation allowing for enhanced conservation of plasma ascorbate.

As discussed previously [15], an important consideration here is whether the putative ability of DCYTB to facilitate ascorbyl radical reduction plays a part in DCYTB-dependent ferrireduction or copper reduction. That is, in the presence of ascorbate, DCYTB may act to facilitate ferrireduction or copper reduction by regenerating extracellular ascorbate, the latter of which has been shown to be effective in facilitating the direct and rapid reduction of iron prior to its cellular uptake [15,22,23,41,97]. In addition to ascorbate cycling across the plasma membrane [22,23,41], this could then be another mechanism by which cells actively maintain a pool of vicinal extracellular ascorbate to facilitate extracellular ferrireduction, and potentially copper reduction as well.

Thus, in addition to being ascorbate being an important source of reducing equivalents for DCYTB, this protein may also be actively involved in the conservation of the reduced form of the vitamin in the extracellular space. Whether this activity is directly involved in duodenal iron or copper reduction prior to absorption has yet to be examined.

\section{Coordination of Systemic and Dietary Iron Absorption: Role of the IRP1-HIF2 $\alpha$ Axis}

\subsection{The IRP-IRE System}

Cellular iron homeostasis is controlled mainly at the post-transcriptional and transcriptional levels. The front-line regulation of cellular iron homeostasis occurs by a post-transcriptional mechanism that controls the rate of synthesis of key iron metabolism proteins involved in iron uptake, storage and release $[1,12,108]$. The IRP-IRE system is responsible for this post-transcriptional regulation, and allows for rapid alterations in translation of key iron metabolism proteins in response to intracellular iron [1,12,109]. This system depends on the mRNA-binding proteins, IRPs-1 and -2, which post-transcriptionally control the expression of mRNAs possessing IREs [1,12,109]. The IRPs bind to IREs in the 5'- or 3'-untranslated regions (UTRs) of key mRNAs involved in iron metabolism with varying and high affinities in iron-depleted cells [12,14]. When cellular iron levels are increased, which can be potentiated by ascorbate [49], IRP1 molecules increasingly lose their IRE-binding activity by acquiring a (4Fe-4S) ISC [109]. The biogenesis of this ISC within IRP1 occurs within the cytosolic ISC biogenesis (CIA) pathway, and is directly regulated by the activity of the 'CIA targeting complex', formed by the CIA ISC targeting proteins, CIA1, CIA2A and MMS19 [110]. The acquisition of this (4Fe-4S) cluster converts IRP1 into a cytosolic aconitase, and thus IRP1's conversion to the ISC-containing form is dependent on active ISC biogenesis in the mitochondria and/or the cytosol [109]. IRP2 is unable to acquire an ISC [111], and it is instead regulated at the level of protein abundance by proteasomal degradation via the IRP2-targeting E3 ubiquitin ligase subunit, F-box and leucine-rich 
repeat protein 5 (FBXL5); a protein which itself is regulated at the level of protein stability by iron and oxygen [112,113]. For recent reviews of the IRP/IRE system in iron homeostasis, see [114-116].

IRP1 and IRP2 have overlapping functions, as only $\operatorname{Irp} 1^{-/-} / \operatorname{Irp} 2^{-/-}$mice demonstrate embryonic lethality, while singly IRP deficient mice (i.e., $\operatorname{Irp}^{-/-}$or $\operatorname{Irp} 2^{-/-}$) remain viable and fertile [117]. Moreover, conditional deletion of both Irp1 and Irp2 in hepatocytes and the intestine results in death of affected mice at around 12 days and 4 weeks of age, respectively [118,119]. Furthermore, conditional deletion of both Irp1 and Irp2 in murine hepatocytes leads to deficiencies in ISC biogenesis and mitochondrial iron supply, suggesting that the IRPs are crucial for the delivery of iron to mitochondria [119].

Irp $2^{-/-}$mice display dysregulated iron metabolism in the duodenum, CNS and motor neurons of the spinal cord [120]. This dysregulation of iron metabolism is evidenced by an increase in ferritin synthesis, and decrease in TfR1 expression, within the duodenum, CNS and brain neurons [120]. These effects are coupled with pronounced accumulation of iron in the duodenal mucosa and within neurons and oligodendrocytes in distinct brain regions [120]. These findings indicate that IRP2 is critical for regulation of iron metabolism in the duodenum and at least parts of the CNS (for a recent review, see Zhang et al. [116]). Crucially, these mice also display a microcytic hypochromic anemia, indicating that IRP2 is also crucial for regulation of iron metabolism in the erythropoietic compartment $[121,122]$. In these animals, the erythroblasts demonstrate decreased TfR1 expression, leading to decreased TfR1-dependent iron uptake, and increased production of protoporphyrin IX (the iron-devoid heme precursor), which is probably due to increased expression of the erythroid-specific isoform of the first enzyme in the heme synthesis pathway, $\delta$-aminoleuvulinate synthase. The mRNA for this protein possesses an IRE in its 5'-UTR, and its synthesis is consequently upregulated by decreased IRE-binding activity.

While $\operatorname{Irp} 1^{-/-}$mice at first appeared asymptomatic when maintained on a normal iron diet, it is now clear that IRP1 plays crucial roles in the regulation of systemic iron homeostasis and erythropoiesis (for a recent review, see Zhang et al. [116]). Interestingly, $\operatorname{Irp} 1^{-/-}$mice have a tendency towards higher hematocrits (i.e., polycythemia) in older animals [121,123], as well as pulmonary hypertension, both of which are exacerbated by a low-iron diet [124]. Additionally, serum erythropoietin (EPO) levels of Irp $1^{-/-}$mice are markedly greater (i.e., >7-fold) than in wildtype mice on an iron-deficient diet [124]. Furthermore, these animals exhibit both splenomegaly and increased splenic erythropoiesis, which suggests that loss of IRP1 in these animals leads to the increased renal production of EPO and EPO-dependent extramedullary erythropoiesis (i.e., erythropoiesis occurring outside the bone marrow) [124]. As discussed further below, the molecular basis of this dysregulation of iron metabolism in $\operatorname{Irp} 1^{-/-}$mice appears to be due largely to an increase in HIF $2 \alpha$ expression. Indeed, it now appears that the regulation of HIF $2 \alpha$ translation may be the major target of IRP1-dependent regulation of cell iron metabolism, at least in the duodenum and liver, while IRP2 may be responsible for the IRP-dependent regulation of most other IRE-containing transcripts [125].

\subsection{Emerging Role of the IRP1-HIF2 $\alpha$ Axis—Regulation of Erythropoiesis}

In addition to post-transcriptional regulation, iron homeostasis is also regulated at the level of the transcription of iron metabolism genes. A major regulator of these changes in transcription is the HIF system, which includes the oxygen- and iron-regulated transcription factors, HIF1 $\alpha$ and HIF2 $\alpha$ [126]. 
Low oxygen tensions (i.e., hypoxia), as well as low intracellular iron and ascorbate concentrations, activate HIF1 $\alpha$ and HIF2 $\alpha$-regulated transcription by the increased formation and transcriptional activity of heterodimers of HIF $1 \alpha$ or HIF $2 \alpha$ with the constitutively expressed HIF $1 \beta$ subunit [126]. HIF $1 \alpha$ is ubiquitously expressed, while HIF2 $\alpha$ has a more restricted tissue distribution $[14,127]$. The HIF $\alpha / \beta$ heterodimers form transcription factors that translocate to the nucleus and regulate a range of genes, which possess hypoxia response elements (HREs), encoding proteins important for cellular oxygen homeostasis and the response to hypoxia [126].

Both HIF $1 \alpha$ and HIF $2 \alpha$ are post-translationally regulated at the level of protein degradation in an oxygen-dependent and iron-dependent manner [126]. This occurs by a specific class of 2-oxoglutarate-dependent dioxygenases: the prolyl-4-hydroxylase domain-containing iron-dependent prolyl hydroxylases (PHDs) 1-3, and the asparaginyl hydroxylase, factor inhibiting HIF1 (FIH1) [127]. However, in the case of HIF2 $\alpha$, the inhibitory effect of FIH1 appears to be minor [128]. Under conditions of iron repletion, these hydroxylases are active under the typical oxygen tensions found under cell culture conditions (i.e., 21\%) [127]. These enzymes hydroxylate HIF $\alpha$ proteins at specific proline residues, leading to proteasomal degradation, or at specific asparagine residues, resulting in inactivation of transcriptional activity [127]. Importantly, it is the strict dependence of these hydroxylases on iron that allows cellular iron to modulate HIF-regulated gene expression [127]. The hydroxylated $\alpha$-subunits of HIF are targeted for ubiquitination by the elongin B-elongin C-cullin-2-von Hippel-Lindau (VHL) E3 ubquitin ligase (also known as CRL-2) subunit, which earmarks the proteins for degradation by the proteasome [126].

HIF $2 \alpha$ is the dominant transcription factor in vivo that controls renal production of EPO and subsequent erythropoiesis in response to both oxygen concentration and iron levels [129-131]. It is now apparent that there is a vital intersection between the IRP/IRE and HIF systems that is pivotal to the regulation of systemic iron homeostasis. Indeed, as alluded to above, recent studies indicate that IRP1, but not IRP2 [123,125,132], is a crucial regulator of HIF2 $\alpha$ levels in duodenum, liver and kidney [123-125]. This regulation occurs because of an IRE present in the 5'-UTR of the HIF $2 \alpha$ mRNA, which results in increased translation of HIF $2 \alpha$ in response to a decrease in IRP1-IRE binding activity [133]. In $\operatorname{Irp} 1^{-/-}$ mice, the lack of IRP1 in kidney (specifically renal interstitial fibroblasts) leads to a derepression of HIF $2 \alpha$ translation, leading to increased HIF $2 \alpha$ levels. The increase in HIF $2 \alpha$ leads to upregulation of the transcription of the Epo gene and increased expression of EPO, which is then secreted and stimulates erythrocyte production [116].

Thus, while oxygen (and iron sensing) by the PHD-regulated proteasomal degradation system regulate HIF2 $\alpha$ protein degradation (see above), the IRP1-modulated regulation of HIF2 $\alpha$ translation allows for fine-tuning of the level of HIF $2 \alpha$ in renal interstitial fibroblasts so that EPO-dependent erythropoiesis does not consume excessive iron [116]. That is, IRP1-dependent sensing of low circulating levels of iron, via decreased production of the ISC in IRP1 and increased IRP1-IRE binding, leads to repression of HIF $2 \alpha$ translation and a consequent decrease in EPO transcription, ensuring that EPO production does not continue unabated when circulating iron levels become depleted by erythropoiesis. 
Importantly, other key HIF2 $\alpha$ targets include DMT1, FPN1 and DCYTB [134-136]. As such, Irp1 $1^{-/-}$ mice show enhanced levels of HIF $2 \alpha$ in duodenum, which results in an increase in duodenal DMT1, FPN1 and DCYTB (discussed further in Section 3.3 below). As these animals also display enhanced erythropoiesis due to a HIF2 $\alpha$-dependent increase in renal EPO production [125], these results suggest that the IRP1-HIF2 $\alpha$ axis is crucial for coordinating erythropoiesis and dietary iron absorption with iron and oxygen sensing [125].

In summary, the IRP1-HIF2 $\alpha$ axis is crucial to the regulation of both iron and oxygen sensing with erythropoiesis and dietary iron absorption [123,125].

\subsection{Emerging Role of the IRP1-HIF $2 \alpha$ axis-Regulation of Duodenal Iron Absorption}

Shortly after the discovery of DCYTB, both DCYTB and DMT1 were found to be downregulated in mice shortly after they were provided with a large oral iron bolus [137]. This behavior provides a likely mechanism for the phenomenon of "mucosal block", which occurs when the absorption of a low dose of iron is downregulated by a preceding large iron bolus provided several hours earlier [137-139]. The phenomenon of mucosal block is of great importance to the field of iron homeostasis and iron deficiency, as it pertains to the ability of the duodenum to act as both an important sensor iron levels that can potentially act independently of the hepcidin-FPN1 axis [140,141].

How is DCYTB regulated by duodenal iron levels? The initial answer to this question came from two studies published in 2009 that indicated that DCYTB and DMT1 can be up-regulated via HIF2 $\alpha$-dependent transcription of their respective genes [134,135] (Figure 2). Unlike the +IRE isoforms of DMT1 (the main isoform expressed in the duodenum), DCYTB mRNA contains no known IREs and cannot be directly regulated by the IRP-IRE system. These studies indicate that HIF2 $\alpha$ is a crucial regulator of duodenal iron absorption that may operate independently of the systemic iron homeostatic regulators (e.g., hepcidin) [134,135,140].

FPN1 [136] is also positively regulated by HIF2 $\alpha$-dependent transcription, although it can also be regulated by the IRP-IRE system in virtue of the IRE in its 5'-UTR [134]. An important complicating factor to this story is that, as a consequence of the IRE in its 5'-UTR, HIF2 $\alpha$ is itself post-transcriptionally regulated by IRP1 in the duodenal epithelium [123,125]. This is in addition to the iron-dependent regulation of HIF $2 \alpha$ at the post-translational level by the PHDs [140]. Thus, the IRP1-HIF2 $\alpha$ axis appears to be a crucial regulator of DCYTB in duodenal enterocytes and an important contributor to the mechanism by which dietary iron absorption is regulated by dietary iron and hypoxia (Figure 2). This has important ramifications for our understanding of the mechanisms of iron deficiency anemia and the possible role of DCYTB in this condition. 

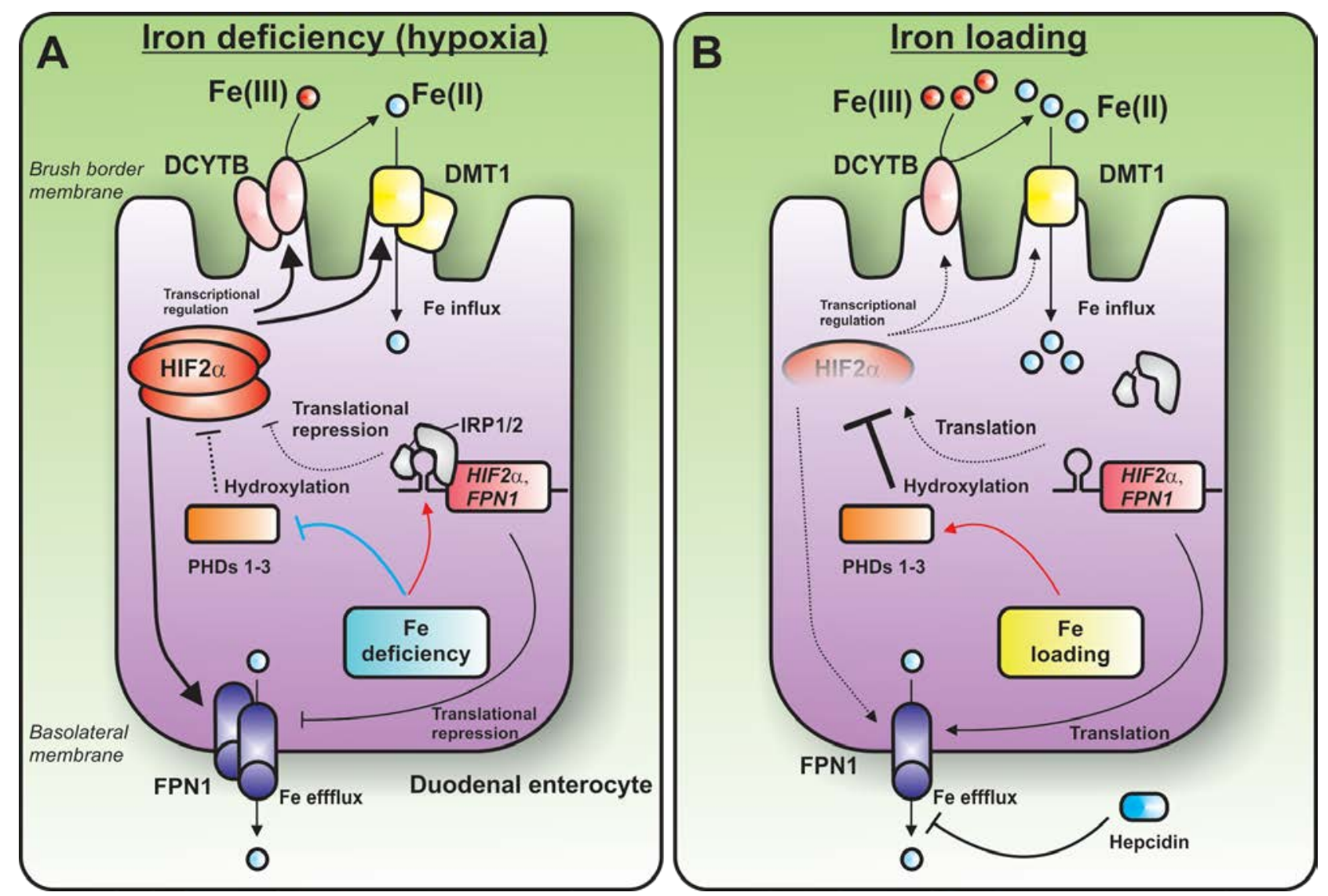

Figure 2. Model for the IRP1-HIF2 $\alpha$ axis in regulating DCYTB and dietary iron absorption.

(A) Under conditions of iron deficiency (as well as hypoxia or increased erythropoietic drive), the expression of HIF2 $\alpha$ is increased in the duodenal enterocyte. This leads to transcriptional up-regulation of key iron-metabolism proteins, including DCYTB, DMT1 and FPN1. Specifically, the increase in HIF2 $\alpha$ leads to an augmentation of DCYTB and DMT1 in the brush border (i.e., apical) membrane of the duodenal enterocyte and an increase in FPN1 levels in the basolateral membrane. HIF2 $\alpha$ has been shown to bind to HRE elements in the regulatory regions of the promoters for DCYTB and DMT1. HIF2 $\alpha$ is also regulated at the post-transcriptional level (as a consequence of the IRE in its 5'-UTR) and post-translational level (as a consequence of PHD activity). Under conditions of iron deficiency in the duodenum, although the increased IRE-binding activity of the IRP1 would tend to decrease HIF $2 \alpha$ translation, the stabilizing effect of low PHD activity on HIF $2 \alpha$ protein levels may predominate, leading to a net increase in HIF2 $\alpha$ and a consequent upregulation of DCYTB and DMT1. (B) In contrast, under conditions of high iron in the duodenum, HIF2 $\alpha$ is translationally derepressed by IRP1, yet PHD activity is likely to be increased, leading to increased HIF $2 \alpha$ hydroxylation and proteasomal degradation. The net effect is a decrease in HIF2 $\alpha$ levels, resulting in decreased DCYTB, DMT1 and perhaps FPN1 levels.

How does the IRP1-HIF2 $\alpha$ axis regulate iron absorption genes in vivo? Under conditions of iron deficiency, hypoxia or increased erythropoietic drive, HIF2 $\alpha$ levels are increased in the duodenal epithelium [140,142]. This leads to transcriptional up-regulation of key iron-metabolism proteins, including 
DCYTB, DMT1 and FPN1 [134-136,142]. Specifically, the increase in HIF2 $\alpha$ leads to an increase in DCYTB and DMT1 in the brush border (i.e., apical) membrane of the duodenal enterocyte [134] and an increase in FPN1 levels in the basolateral membrane [136]. At least in the case of DCYTB and DMT1, HIF2 $\alpha$ has been shown to bind to HRE elements in the regulatory regions of the promoters in their respective genes [134]. HIF2 $\alpha$ is regulated at the post-transcriptional level as a consequence of the IRE in its 5'-UTR, and at the post-translational level as a consequence of PHD activity [140]. Under conditions of iron deficiency in the duodenum, although the increased IRE-binding activity of the IRPs would tend to decrease HIF2 $\alpha$ translation, the stabilizing effect of low PHD activity may predominate, leading to a net increase in HIF2 $\alpha$ and a consequent up-regulation of DCYTB and DMT1 [140] (Figure 2A). In contrast, under conditions of high iron in the duodenum, HIF2 $\alpha$ is translationally derepressed by the IRP-IRE system, yet PHD activity is likely to be increased [140] (Figure 2B). This response may lead to a net decrease in HIF2 $\alpha$ (as a consequence of the enhanced activities of the PHDs) resulting in decreased DCYTB and DMT1 levels. Additionally, under conditions of hypoxia, both HIF $2 \alpha$ and DCYTB increase within several hours of hypoxia, while a change in hepcidin expression, which is also regulated by the HIF system, is increased by 72 h [142]. These latter findings suggest that HIF $2 \alpha$ predominates over hepcidin in the regulation of intestinal iron absorption during short hypoxic stimulation, and that the intestine exerts regulation over dietary absorption that is independent of the hepcidin-FPN1 axis [142].

\section{Conclusions}

In this review, we have discussed the emerging role of DCYTB and ascorbate in iron absorption and iron homeostasis. Iron and ascorbate are vital cellular constituents in mammalian systems, with the bulk-requirement for iron being during erythropoiesis. Iron homeostasis is controlled at the level of uptake, rather than excretion, and accumulating evidence strongly suggests that in addition to the known ability of dietary ascorbate to enhance non-heme iron absorption in the gut, ascorbate regulates iron homeostasis. While the mechanisms of ascorbate's involvement in dietary iron absorption are unclear, ascorbate appears to be involved in the provision of electrons to a family of trans-membrane redox enzymes, namely those of the cytochrome $b_{561}$ class. These hemoproteins oxidize a pool of ascorbate on one side of the membrane in order to reduce an electron acceptor (e.g., non-heme iron) on the opposite side of the membrane. One crucial member of this family, DCYTB, appears to play an important role in reducing non-heme iron in the gut prior to uptake by ferrous-iron transporters. Accumulating evidence suggests a scenario in which DCYTB is regulated by HIF2 $\alpha$ in coordination with IRP1 and PHDs in the duodenal mucosa, particularly in response to iron deficiency and hypoxia. The vital role of DCYTB in dietary iron absorption has important ramifications for our understanding of dietary iron absorption, systemic iron homeostasis and the contributions of DCYTB and ascorbate to iron deficiency anemia.

\section{Acknowledgments}

D.J.R.L. thanks the Cancer Institute New South Wales for an Early Career Fellowship (10/ECF/2-18), the National Health and Medical Research Council (NHMRC) of Australia for an Early Career Postdoctoral Fellowship (1013810), and the Sydney Medical School Foundation for Fellowship support. 
S.S. thanks the University of Sydney for an Early Career Research Grant 2015. D.R.R. thanks the NHMRC for a Senior Principal Research Fellowship (1062607) and Project Grants (1060482, 1062026).

\section{Author Contributions}

D.J.R.L., D.-H.B., A.M.M., S.S. and D.R.R. wrote the manuscript.

\section{Conflicts of Interest}

The authors declare no conflict of interest.

\section{References}

1. Muckenthaler, M.U.; Galy, B.; Hentze, M.W. Systemic iron homeostasis and the iron-responsive element/iron-regulatory protein (IRE/IRP) regulatory network. Annu. Rev. Nutr. 2008, 28, 197-213.

2. Dunn, L.L.; Rahmanto, Y.S.; Richardson, D.R. Iron uptake and metabolism in the new millennium. Trends Cell Biol. 2007, 17, 93-100.

3. Lawen, A.; Lane, D.J.R. Mammalian iron homeostasis in health and disease: Uptake, storage, transport, and molecular mechanisms of action. Antioxid. Redox Signal. 2013, 18, 2473-2507.

4. Steinbicker, A.U.; Muckenthaler, M.U. Out of balance-Systemic iron homeostasis in iron-related disorders. Nutrients 2013, 5, 3034-3061.

5. Arosio, P.; Levi, S. Cytosolic and mitochondrial ferritins in the regulation of cellular iron homeostasis and oxidative damage. Biochim. Biophys. Acta 2010, 1800, 783-792.

6. Lill, R. Function and biogenesis of iron-sulphur proteins. Nature 2009, 460, 831-838.

7. Rouault, T.A. Biogenesis of iron-sulfur clusters in mammalian cells: New insights and relevance to human disease. Dis. Model. Mech. 2012, 5, 155-164.

8. Lane, D.J.R.; Merlot, A.M.; Huang, M.L.-H.; Bae, D.-H.; Jansson, P.J.; Sahni, S.; Kalinowski, D.S.; Richardson, D.R. Cellular iron uptake, trafficking and metabolism: Key molecules and mechanisms and their roles in disease. Biochim. Biophys. Acta. 2015, 1853, 1130-1144.

9. Philpott, C.C.; Ryu, M.S. Special delivery: Distributing iron in the cytosol of mammalian cells. Front. Pharmacol. 2014, 5, 173, doi:10.3389/fphar.2014.00173.

10. Richardson, D.R.; Lane, D.J.R.; Becker, E.M.; Huang, M.L.; Whitnall, M.; Rahmanto, Y.S.; Sheftel, A.D.; Ponka, P. Mitochondrial iron trafficking and the integration of iron metabolism between the mitochondrion and cytosol. Proc. Natl. Acad. Sci. USA 2010, 107, 10775-10782.

11. Lane, D.J.; Mills, T.M.; Shafie, N.H.; Merlot, A.M.; Saleh Moussa, R.; Kalinowski, D.S.; Kovacevic, Z.; Richardson, D.R. Expanding horizons in iron chelation and the treatment of cancer: Role of iron in the regulation of ER stress and the epithelial-mesenchymal transition. Biochim. Biophys. Acta 2014, 1845, 166-181.

12. Hentze, M.W.; Kuhn, L.C. Molecular control of vertebrate iron metabolism: MRNA-based regulatory circuits operated by iron, nitric oxide, and oxidative stress. Proc. Natl. Acad. Sci. USA 1996, 93, 8175-8182.

13. Richardson, D.R.; Ponka, P. The molecular mechanisms of the metabolism and transport of iron in normal and neoplastic cells. Biochim. Biophys. Acta 1997, 1331, 1-40. 
14. Hentze, M.W.; Muckenthaler, M.U.; Galy, B.; Camaschella, C. Two to tango: Regulation of mammalian iron metabolism. Cell 2010, 142, 24-38.

15. Lane, D.J.R.; Lawen, A. Ascorbate and plasma membrane electron transport-Enzymes vs. efflux. Free Radic. Biol. Med. 2009, 47, 485-495.

16. Linster, C.L.; van Schaftingen, E. Vitamin C. Biosynthesis, recycling and degradation in mammals. FEBS J. 2007, 274, 1-22.

17. Atanassova, B.D.; Tzatchev, K.N. Ascorbic acid-important for iron metabolism. Folia Med. (Plovdiv) 2008, 50, 11-16.

18. Toth, I.; Rogers, J.T.; McPhee, J.A.; Elliott, S.M.; Abramson, S.L.; Bridges, K.R. Ascorbic acid enhances iron-induced ferritin translation in human leukemia and hepatoma cells. J. Biol. Chem. 1995, 270, 2846-2852.

19. Bridges, K.R. Ascorbic acid inhibits lysosomal autophagy of ferritin. J. Biol. Chem. 1987, 262, 14773-14778.

20. Hoffman, K.E.; Yanelli, K.; Bridges, K.R. Ascorbic acid and iron metabolism: Alterations in lysosomal function. Am. J. Clin. Nutr. 1991, 54, 1188S-1192S.

21. Richardson, D.R. Role of ceruloplasmin and ascorbate in cellular iron release. J. Lab. Clin. Med. 1999, 134, 454-465.

22. Lane, D.J.R.; Lawen, A. Non-transferrin iron reduction and uptake are regulated by transmembrane ascorbate cycling in K562 cells. J. Biol. Chem. 2008, 283, 12701-12708.

23. Lane, D.J.R.; Robinson, S.R.; Czerwinska, H.; Bishop, G.M.; Lawen, A. Two routes of iron accumulation in astrocytes: Ascorbate-dependent ferrous iron uptake via the divalent metal transporter (DMT1) plus an independent route for ferric iron. Biochem. J. 2010, 432, 123-132.

24. Chua, A.C.; Graham, R.M.; Trinder, D.; Olynyk, J.K. The regulation of cellular iron metabolism. Crit. Rev. Clin. Lab. Sci. 2007, 44, 413-459.

25. Donovan, A.; Lima, C.A.; Pinkus, J.L.; Pinkus, G.S.; Zon, L.I.; Robine, S.; Andrews, N.C. The iron exporter ferroportin/Slc40a1 is essential for iron homeostasis. Cell Metab. 2005, 1, 191-200.

26. Ward, D.M.; Kaplan, J. Ferroportin-mediated iron transport: Expression and regulation. Biochim. Biophys. Acta 2012, 1823, 1426-1433.

27. De Domenico, I.; Ward, D.M.; Langelier, C.; Vaughn, M.B.; Nemeth, E.; Sundquist, W.I.; Ganz, T.; Musci, G.; Kaplan, J. The molecular mechanism of hepcidin-mediated ferroportin down-regulation. Mol. Biol. Cell 2007, 18, 2569-2578.

28. Park, C.H.; Valore, E.V.; Waring, A.J.; Ganz, T. Hepcidin, a urinary antimicrobial peptide synthesized in the liver. J. Biol. Chem. 2001, 276, 7806-7810.

29. Nemeth, E.; Tuttle, M.S.; Powelson, J.; Vaughn, M.B.; Donovan, A.; Ward, D.M.; Ganz, T.; Kaplan, J. Hepcidin regulates cellular iron efflux by binding to ferroportin and inducing its internalization. Science 2004, 306, 2090-2093.

30. Peslova, G.; Petrak, J.; Kuzelova, K.; Hrdy, I.; Halada, P.; Kuchel, P.W.; Soe-Lin, S.; Ponka, P.; Sutak, R.; Becker, E.; et al. Hepcidin, the hormone of iron metabolism, is bound specifically to a-2-macroglobulin in blood. Blood 2009, 113, 6225-6236.

31. Huang, M.L.; Austin, C.J.; Sari, M.A.; Suryo Rahmanto, Y.; Ponka, P.; Vyoral, D.; Richardson, D.R. Hepcidin bound to $\alpha_{2}$-macroglobulin reduces ferroportin-1 expression and enhances its activity at reducing serum iron levels. J. Biol. Chem. 2013, 288, 25450-25465. 
32. Ganz, T.; Nemeth, E. Hepcidin and iron homeostasis. Biochim. Biophys. Acta 2012, 1823, 1434-1443.

33. Kautz, L.; Nemeth, E. Molecular liaisons between erythropoiesis and iron metabolism. Blood 2014, 124, 479-482.

34. Gulec, S.; Anderson, G.J.; Collins, J.F. Mechanistic and regulatory aspects of intestinal iron absorption. Am. J. Physiol. Gastrointest. Liver Physiol. 2014, 307, G397-G409.

35. Anderson, G.J.; Darshan, D.; Wilkins, S.J.; Frazer, D.M. Regulation of systemic iron homeostasis: How the body responds to changes in iron demand. Biometals 2007, 20, 665-674.

36. Sharp, P.A. Intestinal iron absorption: Regulation by dietary \& systemic factors. Int. J. Vitam. Nutr. Res. 2010, 80, 231-242.

37. Pollack, S.; Kaufman, R.; Crosby, W.H.; Butkiewicz, J.E. Reducing agents and absorption of iron. Nature 1963, 199, 384.

38. McKie, A.T.; Barrow, D.; Latunde-Dada, G.O.; Rolfs, A.; Sager, G.; Mudaly, E.; Mudaly, M.; Richardson, C.; Barlow, D.; Bomford, A.; et al. An iron-regulated ferric reductase associated with the absorption of dietary iron. Science 2001, 291, 1755-1759.

39. Asard, H.; Barbaro, R.; Trost, P.; Berczi, A. Cytochromes b561: Ascorbate-mediated trans-membrane electron transport. Antioxid. Redox Signal. 2013, 19, 1026-1035.

40. McKie, A.T. The role of Dcytb in iron metabolism: An update. Biochem. Soc. Trans. 2008, 36, 1239-1241.

41. May, J.M.; Qu, Z.-C.; Mendiratta, S. Role of ascorbic acid in transferrin-independent reduction and uptake of iron by U-937 cells. Biochem. Pharmacol. 1999, 57, 1275-1282.

42. Cakmak, I.; van de Wetering, D.A.M.; Marschner, H.; Bienfait, H.F. Involvement of superoxide radical in extracellular ferric reduction by iron-deficient bean roots. Plant Physiol. 1987, 85, 310-314.

43. Ghio, A.J.; Nozik-Grayck, E.; Turi, J.; Jaspers, I.; Mercatante, D.R.; Kole, R.; Piantadosi, C.A. Superoxide-dependent iron uptake: A new role for anion exchange protein 2. Am. J. Respir. Cell Mol. Biol. 2003, 29, 653-660.

44. Fleming, M.D.; Trenor, C.C., 3rd; Su, M.A.; Foernzler, D.; Beier, D.R.; Dietrich, W.F.; Andrews, N.C. Microcytic anaemia mice have a mutation in Nramp2, a candidate iron transporter gene. Nat. Genet. 1997, 16, 383-386.

45. Liuzzi, J.P.; Aydemir, F.; Nam, H.; Knutson, M.D.; Cousins, R.J. Zip14 (Slc39a14) mediates non-transferrin-bound iron uptake into cells. Proc. Natl. Acad. Sci. USA 2006, 103, 13612-13617.

46. McKie, A.T.; Marciani, P.; Rolfs, A.; Brennan, K.; Wehr, K.; Barrow, D.; Miret, S.; Bomford, A.; Peters, T.J.; Farzaneh, F.; et al. A novel duodenal iron-regulated transporter, IREG1, implicated in the basolateral transfer of iron to the circulation. Mol. Cell 2000, 5, 299-309.

47. Vulpe, C.D.; Kuo, Y.M.; Murphy, T.L.; Cowley, L.; Askwith, C.; Libina, N.; Gitschier, J.; Anderson, G.J. Hephaestin, a ceruloplasmin homologue implicated in intestinal iron transport, is defective in the sla mouse. Nat. Genet. 1999, 21, 195-199.

48. Chen, H.; Attieh, Z.K.; Su, T.; Syed, B.A.; Gao, H.; Alaeddine, R.M.; Fox, T.C.; Usta, J.; Naylor, C.E.; Evans, R.W.; et al. Hephaestin is a ferroxidase that maintains partial activity in sex-linked anemia mice. Blood 2004, 103, 3933-3939.

49. Lane, D.J.; Richardson, D.R. The active role of vitamin C in mammalian iron metabolism: Much more than just enhanced iron absorption! Free Radic. Biol. Med. 2014, 75C, 69-83. 
50. Lane, D.J.R.; Chikhani, S.; Richardson, V.; Richardson, D.R. Transferrin iron uptake is stimulated by ascorbate via an intracellular reductive mechanism. Biochim. Biophys. Acta 2013, 1833, 1527-1541.

51. Toth, I.; Bridges, K.R. Ascorbic acid enhances ferritin mRNA translation by an IRP/aconitase switch. J. Biol. Chem. 1995, 270, 19540-19544.

52. Scheers, N.; Sandberg, A.S. Iron transport through ferroportin is induced by intracellular ascorbate and involves IRP2 and HIF2 $\alpha$. Nutrients 2014, 6, 249-260.

53. Su, D.; Asard, H. Three mammalian cytochromes $b_{561}$ are ascorbate-dependent ferrireductases. FEBS J. 2006, 273, 3722-3734.

54. Fleming, P.J.; Kent, U.M. Cytochrome b561, ascorbic acid, and transmembrane electron transfer. Am. J. Clin. Nutr. 1991, 54, 1173S-1178S.

55. Spiro, M.J.; Ball, E.G. Studies on the respiratory enzymes of the adrenal gland. I. The medulla. J. Biol. Chem. 1961, 236, 225-230.

56. Flatmark, T.; Terland, O. Cytochrome b-561 of the bovine adrenal chromaffin granules. A high potential b-type cytochrome. Biochim. Biophys. Acta 1971, 253, 487-491.

57. Terland, O.; Flatmark, T. Oxidoreductase activities of chromaffin granule ghosts isolated from the bovine adrenal medulla. Biochim. Biophys. Acta 1980, 597, 318-330.

58. Ichikawa, Y.; Yamano, T. Cytochrome 559 in the microsomes of the adrenal medulla. Biochem. Biophys. Res. Commun. 1965, 20, 263-268.

59. Njus, D.; Knoth, J.; Cook, C.; Kelly, P.M. Electron transfer across the chromaffin granule membrane. J. Biol. Chem. 1983, 258, 27-30.

60. Kelley, P.M.; Njus, D. Cytochrome $b_{561}$ spectral changes associated with electron transfer in chromaffin-vesicle ghosts. J. Biol. Chem. 1986, 261, 6429-6432.

61. Wakefield, L.M.; Cass, A.E.; Radda, G.K. Electron transfer across the chromaffin granule membrane. Use of EPR to demonstrate reduction of intravesicular ascorbate radical by the extravesicular mitochondrial NADH: Ascorbate radical oxidoreductase. J. Biol. Chem. 1986, 261, 9746-9752.

62. Njus, D.; Kelley, P.M. The secretory-vesicle ascorbate-regenerating system: A chain of concerted $\mathrm{H}^{+} / \mathrm{e}^{-}$-transfer reactions. Biochim. Biophys. Acta 1993, 1144, 235-248.

63. Jalukar, V.; Kelley, P.M.; Njus, D. Reaction of ascorbic acid with cytochrome $b_{561}$. Concerted electron and proton transfer. J. Biol. Chem. 1991, 266, 6878-6882.

64. Tsubaki, M.; Takeuchi, F.; Nakanishi, N. Cytochrome $b_{561}$ protein family: Expanding roles and versatile transmembrane electron transfer abilities as predicted by a new classification system and protein sequence motif analyses. Biochim. Biophys. Acta 2005, 1753, 174-190.

65. Nakanishi, N.; Takeuchi, F.; Tsubaki, M. Histidine cycle mechanism for the concerted proton/electron transfer from ascorbate to the cytosolic haem $b$ centre of cytochrome $b_{561}$ : A unique machinery for the biological transmembrane electron transfer. J. Biochem. 2007, 142, 553-560.

66. Lu, P.; Ma, D.; Yan, C.; Gong, X.; Du, M.; Shi, Y. Structure and mechanism of a eukaryotic transmembrane ascorbate-dependent oxidoreductase. Proc. Natl. Acad. Sci. USA. 2014, 111, 1813-1818.

67. Zhang, D.-L.; Su, D.; Bérczi, A.; Vargas, A.; Asard, H. An ascorbate-reducible cytochrome $b_{561}$ is localized in macrophage lysosomes. Biochim. Biophys. Acta 2006, 1760, 1903-1913. 
68. Vargas, J.D.; Herpers, B.; McKie, A.T.; Gledhill, S.; McDonnell, J.; van den Heuvel, M.; Davies, K.E.; Ponting, C.P. Stromal cell-derived receptor 2 and cytochrome $b_{561}$ are functional ferric reductases. Biochim. Biophys. Acta 2003, 1651, 116-123.

69. Picco, C.; Scholz-Starke, J.; Naso, A.; Preger, V.; Sparla, F.; Trost, P.; Carpaneto, A. How are cytochrome B561 electron currents controlled by membrane voltage and substrate availability? Antioxid. Redox Signal. 2014, 21, 384-391.

70. Mizutani, A.; Sanuki, R.; Kakimoto, K.; Kojo, S.; Taketani, S. Involvement of 101F6, a homologue of cytochrome $b_{561}$, in the reduction of ferric ions. J. Biochem. 2007, 142, 699-705.

71. Recuenco, M.C.; Rahman, M.M.; Takeuchi, F.; Kobayashi, K.; Tsubaki, M. Electron transfer reactions of candidate tumor suppressor 101F6 protein, a cytochrome $b_{561}$ homologue, with ascorbate and monodehydroascorbate radical. Biochemistry 2013, 52, 3660-3668.

72. Wyman, S.; Simpson, R.J.; McKie, A.T.; Sharp, P.A. Dcytb (Cybrd1) functions as both a ferric and a cupric reductase in vitro. FEBS Lett. 2008, 582, 1901-1906.

73. Turi, J.L.; Wang, X.; McKie, A.T.; Nozik-Grayck, E.; Mamo, L.B.; Crissman, K.; Piantadosi, C.A.; Ghio, A.J. Duodenal cytochrome B: A novel ferrireductase in airway epithelial cells. Am. J. Physiol. Lung Cell. Mol. Physiol. 2006, 291, L272-L280.

74. Berczi, A.; Zimanyi, L.; Asard, H. Dihydrolipoic acid reduces cytochrome $b_{561}$ proteins. Eur. Biophys. J. 2013, 42, 159-168.

75. May, J.M.; Qu, Z.-C.; Nelson, D.J. Uptake and reduction of $\alpha$-lipoic acid by human erythrocytes. Clin. Biochem. 2007, 40, 1135-1142.

76. Jones, W.; Li, X.; Qu, Z.-C.; Perriott, L.; Whitesell, R.R.; May, J.M. Uptake, recycling, and antioxidant actions of $\alpha$-lipoic acid in endothelial cells. Free Radic. Biol. Med. 2002, 33, 83-93.

77. Latunde-Dada, G.O.; van der Westhuizen, J.; Vulpe, C.D.; Anderson, G.J.; Simpson, R.J.; McKie, A.T. Molecular and functional roles of duodenal cytochrome B (Dcytb) in iron metabolism. Blood Cells Mol. Dis. 2002, 29, 356-360.

78. Oakhill, J.S.; Marritt, S.J.; Gareta, E.G.; Cammack, R.; McKie, A.T. Functional characterization of human duodenal cytochrome $b$ (Cybrd1): Redox properties in relation to iron and ascorbate metabolism. Biochim. Biophys. Acta. 2008, 1777, 260-268.

79. Latunde-Dada, G.O.; Simpson, R.J.; McKie, A.T. Duodenal cytochrome b expression stimulates iron uptake by human intestinal epithelial cells. J. Nutr. 2008, 138, 991-995.

80. Vlachodimitropoulou, E.; Naftalin, R.J.; Sharp, P.A. Quercetin is a substrate for the transmembrane oxidoreductase Dcytb. Free Radic. Biol. Med. 2010, 48, 1366-1369.

81. Hertog, M.G.; Hollman, P.C.; Katan, M.B.; Kromhout, D. Intake of potentially anticarcinogenic flavonoids and their determinants in adults in The Netherlands. Nutr. Cancer 1993, 20, 21-29.

82. Strobel, P.; Allard, C.; Perez-Acle, T.; Calderon, R.; Aldunate, R.; Leighton, F. Myricetin, quercetin and catechin-gallate inhibit glucose uptake in isolated rat adipocytes. Biochem. J. 2005, 386, 471-478.

83. Park, J.B.; Levine, M. Intracellular accumulation of ascorbic acid is inhibited by flavonoids via blocking of dehydroascorbic acid and ascorbic acid uptakes in HL-60, U937 and Jurkat cells. J. Nutr. 2000, 130, 1297-1302.

84. Cunningham, P.; Afzal-Ahmed, I.; Naftalin, R.J. Docking studies show that L-glucose and quercetin slide through the transporter GLUT1. J. Biol. Chem. 2006, 281, 5797-5803. 
85. Vlachodimitropoulou, E.; Sharp, P.A.; Naftalin, R.J. Quercetin-iron chelates are transported via glucose transporters. Free Radic. Biol. Med. 2011, 50, 934-944.

86. Ludwiczek, S.; Rosell, F.I.; Ludwiczek, M.L.; Mauk, A.G. Recombinant expression and initial characterization of the putative human enteric ferric reductase Dcytb. Biochemistry 2008, 47, 753-761.

87. Constantine, C.C.; Anderson, G.J.; Vulpe, C.D.; McLaren, C.E.; Bahlo, M.; Yeap, H.L.; Gertig, D.M.; Osborne, N.J.; Bertalli, N.A.; Beckman, K.B.; et al. A novel association between a SNP in CYBRD1 and serum ferritin levels in a cohort study of HFE hereditary haemochromatosis. Br. J. Haematol. 2009, 147, 140-149.

88. Gunshin, H.; Starr, C.N.; Direnzo, C.; Fleming, M.D.; Jin, J.; Greer, E.L.; Sellers, V.M.; Galica, S.M.; Andrews, N.C. Cybrd1 (duodenal cytochrome $b$ ) is not necessary for dietary iron absorption in mice. Blood 2005, 106, 2879-2883.

89. Atanasova, B.; Mudway, I.S.; Laftah, A.H.; Latunde-Dada, G.O.; McKie, A.T.; Peters, T.J.; Tzatchev, K.N.; Simpson, R.J. Duodenal ascorbate levels are changed in mice with altered iron metabolism. J. Nutr. 2004, 134, 501-505.

90. Rathbone, B.J.; Johnson, A.W.; Wyatt, J.I.; Kelleher, J.; Heatley, R.V.; Losowsky, M.S. Ascorbic acid: A factor concentrated in human gastric juice. Clin. Sci. (Lond.) 1989, 76, 237-241.

91. Atanasova, B.D.; Li, A.C.; Bjarnason, I.; Tzatchev, K.N.; Simpson, R.J. Duodenal ascorbate and ferric reductase in human iron deficiency. Am. J. Clin. Nutr. 2005, 81, 130-133.

92. Frazer, D.M.; Wilkins, S.J.; Vulpe, C.D.; Anderson, G.J. The role of duodenal cytochrome $b$ in intestinal iron absorption remains unclear. Blood 2005, 106, 4413, doi:10.1182/blood-200507-2923.

93. Choi, J.; Masaratana, P.; Latunde-Dada, G.O.; Arno, M.; Simpson, R.J.; McKie, A.T. Duodenal reductase activity and spleen iron stores are reduced and erythropoiesis is abnormal in Dcytb knockout mice exposed to hypoxic conditions. J. Nutr. 2012, 142, 1929-1934.

94. Su, D.; May, J.M.; Koury, M.J.; Asard, H. Human erythrocyte membranes contain a cytochrome $b_{561}$ that may be involved in extracellular ascorbate recycling. J. Biol. Chem. 2006, 281, 39852-39859.

95. Kovar, J.; Neubauerova, J.; Cimburova, M.; Truksa, J.; Balusikova, K.; Horak, J. Stimulation of non-transferrin iron uptake by iron deprivation in K562 cells. Blood Cells Mol. Dis. 2006, 37, 95-99.

96. Balusikova, K.; Neubauerova, J.; Dostalikova-Cimburova, M.; Horak, J.; Kovar, J. Differing expression of genes involved in non-transferrin iron transport across plasma membrane in various cell types under iron deficiency and excess. Mol. Cell. Biochem. 2009, 321, 123-133.

97. Lane, D.J.R.; Robinson, S.R.; Czerwinska, H.; Lawen, A. A role for $\mathrm{Na}^{+} / \mathrm{H}^{+}$exchangers and intracellular $\mathrm{pH}$ in regulating vitamin $\mathrm{C}$-driven electron transport across the plasma membrane. Biochem. J. 2010, 428, 191-200.

98. Jeong, S.Y.; David, S. Glycosylphosphatidylinositol-anchored ceruloplasmin is required for iron efflux from cells in the central nervous system. J. Biol. Chem. 2003, 278, 27144-27148.

99. Tulpule, K.; Robinson, S.R.; Bishop, G.M.; Dringen, R. Uptake of ferrous iron by cultured rat astrocytes. J. Neurosci. Res. 2010, 88, 563-571. 
100. Knöpfel, M.; Solioz, M. Characterization of a cytochrome $b(558)$ ferric/cupric reductase from rabbit duodenal brush border membranes. Biochem. Biophys. Res. Commun. 2002, 291, 220-225.

101. Sharp, P. The molecular basis of copper and iron interactions. Proc. Nutr. Soc. 2004, 63, 563-569.

102. Nose, Y.; Wood, L.K.; Kim, B.E.; Prohaska, J.R.; Fry, R.S.; Spears, J.W.; Thiele, D.J. Ctr1 is an apical copper transporter in mammalian intestinal epithelial cells in vivo that is controlled at the level of protein stability. J. Biol. Chem. 2010, 285, 32385-32392.

103. Arredondo, M.; Mendiburo, M.J.; Flores, S.; Singleton, S.T.; Garrick, M.D. Mouse divalent metal transporter 1 is a copper transporter in HEK293 cells. Biometals 2014, 27, 115-123.

104. Jiang, L.; Garrick, M.D.; Garrick, L.M.; Zhao, L.; Collins, J.F. Divalent metal transporter 1 (Dmt1) mediates copper transport in the duodenum of iron-deficient rats and when overexpressed in iron-deprived HEK-293 cells. J. Nutr. 2013, 143, 1927-1933.

105. Matak, P.; Zumerle, S.; Mastrogiannaki, M.; el Balkhi, S.; Delga, S.; Mathieu, J.R.; Canonne-Hergaux, F.; Poupon, J.; Sharp, P.A.; Vaulont, S.; et al. Copper deficiency leads to anemia, duodenal hypoxia, upregulation of HIF-2 $\alpha$ and altered expression of iron absorption genes in mice. PLoS ONE 2013, 8, e59538, doi:10.1371/journal.pone.0059538.

106. Xie, L.; Collins, J.F. Transcription factors Sp1 and Hif2 $\alpha$ mediate induction of the copper-transporting ATPase (Atp7a) gene in intestinal epithelial cells during hypoxia. J. Biol. Chem. 2013, 288, 23943-23952.

107. Xie, L.; Collins, J.F. Transcriptional regulation of the Menkes copper ATPase (Atp7a) gene by hypoxia-inducible factor (HIF2 $\alpha$ ) in intestinal epithelial cells. Am. J. Physiol. Cell Physiol. 2011, 300, C1298-C1305.

108. Ponka, P.; Beaumont, C.; Richardson, D.R. Function and regulation of transferrin and ferritin. Semin. Hematol. 1998, 35, 35-54.

109. Rouault, T.A. The role of iron regulatory proteins in mammalian iron homeostasis and disease. Nat. Chem. Biol. 2006, 2, 406-414.

110. Stehling, O.; Mascarenhas, J.; Vashisht, A.A.; Sheftel, A.D.; Niggemeyer, B.; Rosser, R.; Pierik, A.J.; Wohlschlegel, J.A.; Lill, R. Human CIA2A-FAM96A and CIA2B-FAM96B integrate iron homeostasis and maturation of different subsets of cytosolic-nuclear iron-sulfur proteins. Cell Metab. 2013, 18, 187-198.

111. Guo, B.; Phillips, J.D.; Yu, Y.; Leibold, E.A. Iron regulates the intracellular degradation of iron regulatory protein 2 by the proteasome. J. Biol. Chem. 1995, 270, 21645-21651.

112. Salahudeen, A.A.; Thompson, J.W.; Ruiz, J.C.; Ma, H.W.; Kinch, L.N.; Li, Q.; Grishin, N.V.; Bruick, R.K. An E3 ligase possessing an iron-responsive hemerythrin domain is a regulator of iron homeostasis. Science 2009, 326, 722-726.

113. Vashisht, A.A.; Zumbrennen, K.B.; Huang, X.; Powers, D.N.; Durazo, A.; Sun, D.; Bhaskaran, N.; Persson, A.; Uhlen, M.; Sangfelt, O.; et al. Control of iron homeostasis by an iron-regulated ubiquitin ligase. Science 2009, 326, 718-721.

114. Anderson, C.P.; Shen, M.; Eisenstein, R.S.; Leibold, E.A. Mammalian iron metabolism and its control by iron regulatory proteins. Biochim. Biophys. Acta 2012, 1823, 1468-1483.

115. Wilkinson, N.; Pantopoulos, K. The IRP/IRE system in vivo: Insights from mouse models. Front. Pharmacol. 2014, 5, 176, doi:10.3389/fphar.2014.00176. 
116. Zhang, D.L.; Ghosh, M.C.; Rouault, T.A. The physiological functions of iron regulatory proteins in iron homeostasis-An update. Front. Pharmacol. 2014, 5, 124, doi:10.3389/fphar.2014.00124.

117. Meyron-Holtz, E.G.; Ghosh, M.C.; Iwai, K.; LaVaute, T.; Brazzolotto, X.; Berger, U.V.; Land, W.; Ollivierre-Wilson, H.; Grinberg, A.; Love, P.; et al. Genetic ablations of iron regulatory proteins 1 and 2 reveal why iron regulatory protein 2 dominates iron homeostasis. EMBO J. 2004, 23, 386-395.

118. Galy, B.; Ferring-Appel, D.; Kaden, S.; Grone, H.J.; Hentze, M.W. Iron regulatory proteins are essential for intestinal function and control key iron absorption molecules in the duodenum. Cell Metab. 2008, 7, 79-85.

119. Galy, B.; Ferring-Appel, D.; Sauer, S.W.; Kaden, S.; Lyoumi, S.; Puy, H.; Kolker, S.; Grone, H.J.; Hentze, M.W. Iron regulatory proteins secure mitochondrial iron sufficiency and function. Cell Metab. 2010, 12, 194-201.

120. LaVaute, T.; Smith, S.; Cooperman, S.; Iwai, K.; Land, W.; Meyron-Holtz, E.; Drake, S.K.; Miller, G.; Abu-Asab, M.; Tsokos, M.; et al. Targeted deletion of the gene encoding iron regulatory protein-2 causes misregulation of iron metabolism and neurodegenerative disease in mice. Nat. Genet. 2001, 27, 209-214.

121. Cooperman, S.S.; Meyron-Holtz, E.G.; Olivierre-Wilson, H.; Ghosh, M.C.; McConnell, J.P.; Rouault, T.A. Microcytic anemia, erythropoietic protoporphyria, and neurodegeneration in mice with targeted deletion of iron-regulatory protein 2. Blood 2005, 106, 1084-1091.

122. Galy, B.; Ferring, D.; Minana, B.; Bell, O.; Janser, H.G.; Muckenthaler, M.; Schumann, K.; Hentze, M.W. Altered body iron distribution and microcytosis in mice deficient in iron regulatory protein 2 (IRP2). Blood 2005, 106, 2580-2589.

123. Wilkinson, N.; Pantopoulos, K. IRP1 regulates erythropoiesis and systemic iron homeostasis by controlling HIF2 $\alpha$ mRNA translation. Blood 2013, 122, 1658-1668.

124. Ghosh, M.C.; Zhang, D.L.; Jeong, S.Y.; Kovtunovych, G.; Ollivierre-Wilson, H.; Noguchi, A.; Tu, T.; Senecal, T.; Robinson, G.; Crooks, D.R.; et al. Deletion of iron regulatory protein 1 causes polycythemia and pulmonary hypertension in mice through translational derepression of HIF2 $\alpha$. Cell Metab. 2013, 17, 271-281.

125. Anderson, S.A.; Nizzi, C.P.; Chang, Y.I.; Deck, K.M.; Schmidt, P.J.; Galy, B.; Damnernsawad, A.; Broman, A.T.; Kendziorski, C.; Hentze, M.W.; et al. The IRP1-HIF-2 $\alpha$ axis coordinates iron and oxygen sensing with erythropoiesis and iron absorption. Cell Metab. 2013, 17, 282-290.

126. Cassavaugh, J.; Lounsbury, K.M. Hypoxia-mediated biological control. J. Cell Biochem. 2011, 112, 735-744.

127. Mole, D.R. Iron homeostasis and its interaction with prolyl hydroxylases. Antioxid. Redox Signal. 2010, 12, 445-458.

128. Yan, Q.; Bartz, S.; Mao, M.; Li, L.; Kaelin, W.G., Jr. The hypoxia-inducible factor $2 \alpha$ $\mathrm{N}$-terminal and C-terminal transactivation domains cooperate to promote renal tumorigenesis in vivo. Mol. Cell. Biol. 2007, 27, 2092-2102.

129. Semenza, G.L. Hypoxia-inducible factors in physiology and medicine. Cell 2012, 148, 399-408.

130. Semenza, G.L. Involvement of oxygen-sensing pathways in physiologic and pathologic erythropoiesis. Blood 2009, 114, 2015-2019.

131. Haase, V.H. Regulation of erythropoiesis by hypoxia-inducible factors. Blood Rev. 2013, 27, 41-53. 
132. Zimmer, M.; Ebert, B.L.; Neil, C.; Brenner, K.; Papaioannou, I.; Melas, A.; Tolliday, N.; Lamb, J.; Pantopoulos, K.; Golub, T.; et al. Small-molecule inhibitors of HIF-2 $\alpha$ translation link its 5'UTR iron-responsive element to oxygen sensing. Mol. Cell 2008, 32, 838-848.

133. Sanchez, M.; Galy, B.; Muckenthaler, M.U.; Hentze, M.W. Iron-regulatory proteins limit hypoxia-inducible factor-2alpha expression in iron deficiency. Nat. Struct. Mol. Biol. 2007, 14, 420-426.

134. Shah, Y.M.; Matsubara, T.; Ito, S.; Yim, S.H.; Gonzalez, F.J. Intestinal hypoxia-inducible transcription factors are essential for iron absorption following iron deficiency. Cell Metab. 2009, 9, 152-164.

135. Mastrogiannaki, M.; Matak, P.; Keith, B.; Simon, M.C.; Vaulont, S.; Peyssonnaux, C. HIF-2 $\alpha$, but not HIF-1 $\alpha$, promotes iron absorption in mice. J. Clin. Invest. 2009, 119, 1159-1166.

136. Taylor, M.; Qu, A.; Anderson, E.R.; Matsubara, T.; Martin, A.; Gonzalez, F.J.; Shah, Y.M. Hypoxia-inducible factor- $2 \alpha$ mediates the adaptive increase of intestinal ferroportin during iron deficiency in mice. Gastroenterology 2011, 140, 2044-2055.

137. Frazer, D.M.; Wilkins, S.J.; Becker, E.M.; Murphy, T.L.; Vulpe, C.D.; McKie, A.T.; Anderson, G.J. A rapid decrease in the expression of DMT1 and Dcytb but not Ireg1 or hephaestin explains the mucosal block phenomenon of iron absorption. Gut 2003, 52, 340-346.

138. Hahn, P.F.; Bale, W.F.; Ross, J.F.; Balfour, W.M.; Whipple, G.H. Radioactive iron absorption by gastro-intestinal tract: Influence of Anemia, Anoxia, and Antecedent Feeding Distribution in Growing Dogs. J. Exp. Med. 1943, 78, 169-188.

139. Stewart, W.B.; Yuile, C.L.; Claiborne, H.A.; Snowman, R.T.; Whipple, G.H. Radioiron absorption in anemic dogs; fluctuations in the mucosal block and evidence for a gradient of absorption in the gastrointestinal tract. J. Exp. Med. 1950, 92, 375-382.

140. Mastrogiannaki, M.; Matak, P.; Peyssonnaux, C. The gut in iron homeostasis: Role of HIF-2 under normal and pathological conditions. Blood 2013, 122, 885-892.

141. Simpson, R.J.; McKie, A.T. Regulation of intestinal iron absorption: The mucosa takes control? Cell Metab. 2009, 10, 84-87.

142. Latunde-Dada, G.O.; Xiang, L.; Simpson, R.J.; McKie, A.T. Duodenal cytochrome b (Cybrd 1) and HIF-2 $\alpha$ expression during acute hypoxic exposure in mice. Eur. J. Nutr. 2011, 50, 699-704.

(C) 2015 by the authors; licensee MDPI, Basel, Switzerland. This article is an open access article distributed under the terms and conditions of the Creative Commons Attribution license (http://creativecommons.org/licenses/by/4.0/). 